\title{
Monte Carlo Simulation and Modeling of Schedule, Cost and Risks of Dasu Hydropower Project
}

\author{
SAJJAD MUBIN*, SHAH JAHAN**, AND EKATERINA GAVRISHYK*** \\ RECEIVED ON 20.03.2018 ACCEPTED ON 17.08.2018
}

\begin{abstract}
HPP(Hydropower Projects) are very complex and risky in nature. For HPP, it is extremely important not only to identify risks but also to adopt proper mitigation measure to complete the project with in defined schedule and budget. Attempt has been made in this paper to identify critical risks associated with Dasu HPP and their mitigation measure to complete the project within predefined time and budget. The research methodology involved the questionnaire survey for identification of potential risks with their probabilities and impact. Pert-Master (Oracle Risk) software was used for simulation purposes. After feeding all data in the software, Monte Carlo simulation was run at 1,000 iterations to generate most probable duration of project, most probable cost of the project, critical risks sensitive to duration, critical risk sensitive to cost and statistically analyzed critical tasks/activities, which need due consideration for successful completion of project. Simulated schedule and budget was compared with planned one to find possible deviations, which may be eliminated by using mitigation measures proposed in the last section of the paper.
\end{abstract}

Key Words: Hydropower Projects, Monte-Carlo Simulation and Modeling, Risk Assessment and Management.

\section{INTRODUCTION}

$\int^{1}$ nergy crises have been a serious issue in Pakistan for the last two decades. HP is one of the cheapest sources of energy production to overcome these energy issues. On the other hand, it takes times and significant capital investment to complete HPP. Moreover, HPP are subject to a lot of risks and uncertainties. The WAPDA(Water \& Power Development Authority) prepared at twenty-five years development plan named as "Water Resources and Hydro Power Development - Vision 2025 Programme" in 2001. The "Vision 2025 Programme" visualized the Dasu HPP on the upper Indus, regarding its feasibility studies, detailed engineering design and execution. It was revealed that Dasu HPP, in all respects, is a robust and viable project with an excellent economic rate of return to Pakistan [1]. The salient features of Dasu HPP are mentioned in Table 1.

Authors E-Mail. (sajjadmubin@uet.edu.pk, shahjahan_ce@yahoo.com, ekaterina.iol@pu.edu.pk)

* University of Engineering and Technology, Lahore, Pakistan.

** University of Lahore, Gujrat Campus, Gujrat, Pakistan.

*** University of Punjab, Lahore, Pakistan.

This is an open access article published by Mehran University Research Journal of Engineering and Technology, Jamshoro under the CC by 4.0 International License. 
The main focus of this research is to devise a methodology to complete HPP well in planned time and budget. Despite of good economic feasibility, Dasu HPP faces many risks due to its complexity of design, involvement of multi-lateral stakeholders and mass construction. For this purpose, proper scheduling and controlling of project is imperative. However, for such complex projects, facing diverse risks and uncertainties, normal scheduling technique may not be effective and therefore, a risk based scheduling technique should be used. Risk based scheduling technique considers all probable risks of project in planning, scheduling and control of project in order to complete it within planned and pre-defined time, cost and quality. This will only be possible if proper identification and assessment of key risks of the projects are made. Such risks may be categorized as Engineering, Procurement, Contractual, Financial, Construction/Execution, Health and Safety, Security, Natural Climatic \& Environmental or Miscellaneous Risks.

On the basis of identified risks, risks are linked with the schedule, which was developed in Pert-Master software.
Monte Carlo technique was used for simulation. PertMaster software was also used for simulation which takes into account original schedule, a 11 possible critical risks of the project while designing timelines and expected budget of project. Simulation also gives most probable schedule duration, most probable costs and critical risks of project. Moreover, performance indicators such as CPI (Cost Performance Indicator), SPI (Schedule Performance Indicator), CI (Criticality Index), SI (Sensitivity Index) and many others parameters me calculated for effective control of Dasu HPP [2].

As Dasu HPP is a public sector project therefore, it has its own complexities and riskiness due pros and cons of Public sector. Through this research, an attempt has been made to use software based analysis and simulation of scheduling and cost for Dasu HPP and developed methodology can be used as a guideline for the other HPP on Indus and other rivers in Pakistan. The study will also give policy options to Policy makers and other stakeholders about completion of projects in terms of expected cost overrun, expected completion time and critical risks of the project to determine true cost-benefit analysis of the project.

TABLE 1. SALIENT FEATURES OF DASU HYDROPOWER PROJECTS [1]

\begin{tabular}{|c|c|}
\hline \multicolumn{2}{|r|}{ Salient Features } \\
\hline Dam Type & RCC (Gravity Dam) \\
\hline Height of Dam & $242 \mathrm{~m}$ \\
\hline Gross storage capacity & 1410 million $\mathrm{m}^{3}$ \\
\hline Live storage capacity & 820 million $\mathrm{m}^{3}$ \\
\hline $\mathrm{CCA}$ & $158,800 \mathrm{~km}^{2}$ \\
\hline Power Generation & $\begin{array}{ll}\text { - } & \text { Stage-1 }=2,160 \mathrm{MW} \text { - Annual Energy 12,222 (GWh) } \\
\text { - } & \text { Stage- } 2=2,160 \mathrm{MW} \text { - Annual Energy 09,263 (GWh) }\end{array}$ \\
\hline Execution by & Water and Power Development Authority Pakistan \\
\hline Supervision Consultant & $\begin{array}{l}\text { DHC (Dasu Hydropower Consultant) a JV of Nippon Koei (Japan) and } \\
\text { Dolsar (Turkey) with local sub-consultants DMC, NDC and PES }\end{array}$ \\
\hline Contractor of main works & China Gezhouba Group Co. Ltd. \\
\hline Donor Agency & $\begin{array}{c}\bullet \text { World Bank (Main Donor) } \\
- \text { Local Commercial Banks (consortium of seven banks led by Habib Bank Ltd.) } \\
\qquad \text { Credit Suisse Bank } \\
\end{array}$ \\
\hline Commencement Date & Main Civil Works (Dam \& Powerhouse) commenced on June 23, 2017 \\
\hline Completion Date & February, 2023 \\
\hline
\end{tabular}

Mehran University Research Journal of Engineering \& Technology, Volume 38, No. 3, July, 2019 [p-ISSN: 0254-7821, e-ISSN: 2413-7219] 


\section{MATERIALS AND METHODS}

\subsection{Common Risks and Constraints in Public Sector Development Projects}

HPP are mostly undertaken by Public sector under Public Sector Development Plans. In addition to its own technical complexity and riskiness, public sector imposes its own inherent risks on the project. Public sector projects are more prone to delays and cost overrun as compare to private sector projects. Peculiar risks and constraints of public sector development projects mainly increase budget, prolong timelines of the projects and produce reduced quality of work which decreases its benefits, service life, usage and expectations of project stakeholders. In many cases, projects were terminated halfway due to changing Govt. policies or not availability of funds or expertise. Mubin et. al. [3] discussed many factors for occurrence of such incidents including but not limited to;

(a) Delays in project preparation and approvals

(b) Thin funding due to change in Govt. priorities

(c) Significant delays in releases of funds of public projects $\mathrm{p}$

(d) Releases not as per actual allocation in ADP or PSDP

(e) Delays in releases of funds

(f) Bureaucratic barriers and entanglements in project approval process and release of funds

(g) Overall political influence in execution of project and not limiting to project identification and inclusion in ADP or PSDP, fund releases and approvals

(h) Absence of proper economic / financial analysis and feasibilities of project

(i) Legal constraints and litigation with stakeholders (j) Defects and negligence in project planning, designing, resourcing and execution of work

(k) Poor performance by implementing and executing agencies

(l) Weak M\&E (Monitoring and Evaluation) and project management mechanism.

It was also emphasized by Mubin et. al. [3] that around $50 \%$ studied public projects were delayed or revised for extension in time.

\subsection{Overview of Previous Relevant Researches}

Mubin and Mubin [4] earlier studied the Risk Analysis for construction and operation of gas pipeline projects in Pakistan. In their study, simulation based scheduling and budgeting was conducted for construction of Oil and Gas pipelines projects. In this research, probability of risk occurrence " $\mathrm{P}$ " came out to be the function of project duration " $T$ ". This means that riskiness of project increases many fold if timelines of projects are significantly long or extended. Shorter duration projects are lesser prone to risks of delays and cost overrun. However, intensity or impact of risks was found to be a function of enterprise internal and external environment. It means that, economic conditions of the country, vital economic parameters and technological advancement are main factors which determine the impact of risk occurring in the construction of Oil and Gas pipelines projects. They also analyzed three most critical activities and risks of project by using software Risky Project along with giving most probable timelines and cost of studied project. Now the same model is to be adopted for HPP.

Besides, technical complexity and riskiness of HPP, agreed Contracts for construction impose their own inherited risks which significantly contribute in project

Mehran University Research Journal of Engineering \& Technology, Volume 38, No. 3, July, 2019 [p-ISSN: 0254-7821, e-ISSN: 2413-7219] 
delays and cost overrun. There are different types of contracting arrangement which levy different kinds of risks on contracting parties. In HPP or energy projects in Pakistan, Turnkey or EPC (Engineering procurement and Construction) Contracting arrangements is preferred. EPC Contracts are riskiest arrangements for the Contractor as single party is responsible for all works including designing, procurement and construction. In this case, Contractor has to take all risks of the project and bid for a fix price and timeline of project failing to which heavy penalties are imposed by the Client. Moreover, no variations in rates or quantities are allowed. Mubin and Mannan [5] worked on the risk analysis for EPC projects. The study aimed to analyze risks in their projects executed by four EPC companies of Pakistan. Study highlighted number of critical risks for EPC projects. The study recommended that the simulation and risk-based planning, scheduling, estimating and controlling of EPC projects would result in achieving the most probable duration and probable cost which would avoid delays and cost overruns in such projects.

Construction of Dams and HP projects are subject to a lot of health and safety issues and risks on site. Moreover, due to a lot of uncertainties and risks volume of work increases, this may have negative impact on cost and schedule of project. Bowles et. al. [6] studied the applicability of Portfolio Risk Management in Dam Safety. This study results showed that Portfolio Risk Management tool when combined with engineering standards and risk assessment approaches, can be used for providing the systematic means for identification, estimation and evaluation of dam safety risks including comparisons with other industries. Nevertheless, it should be periodically updated to provide a basis for managing prioritized investigation and risk reduction measures.
Simulations are important to workout most probable schedule of project, cost, quality of work, critical risks and other project results. Jiang et. al. [6], worked on simulations of project schedule and cost, before they are started. He highlighted that studies on real-time safety risk assessment aimed at reducing uncertainty and supporting quick response are rare. A method for RTSRA (Real-Time Safety Risk Assessment) to implement a dynamic evaluation of worker safety was modeled in this study. By employing the HMM (Hidden Markov Model), the RTSRA provides a mechanism for processing location data provided by the RTLS (RealTime Location System) and analyzing the probability distributions of different states in terms of false positives and negatives. Simulation analysis demonstrated the logic of the proposed method and how it works. Application case shows that the proposed RTSRA is both feasible and effective in managing construction project safety concerns.

The delays in the public sector development projects are a world-wide phenomenon. The world over, it is regarded and considered as one of the most frequent issues of the development projects and project management. This area directly deals with the governance and public policy too as it focuses or embraces the projects being undertaken or initiated solely or exclusively for the benefit of the people or public at large. The public sector projects anywhere in the world, in particular Pakistan, face numerous potential threats and challenges due to time related factors that drag the project, schedule, cost and quality away from the desired level. By conducting a risk analysis provides a more accurate and realistic estimates of project costs and schedule based on Monte Carlo Simulation using Pert-Master. Jupri et. al. [7], worked on Risk Analysis of Construction Project Scheduling using PERT and Monte Carlo Simulation through a case study. The research work involved use of crystal ball @Risk software for risk analysis, Monte Carlo Simulation and Pert-Master to achieve the goals of study. The research 
methodology involved the questionnaire survey for identification of potential risks with their probabilities and impact. Normal scheduling techniques for a complex project don't work well when there are a lot of risks in the project. Therefore, Jupri et. al. [7] in their research worked on the schedule of the project prepared in the MS Project software was transformed to Pert-Master for incorporating such risks which were relevant to the specific project activities to find out the probable date of completion with the given data. Major risk sources found out in the study are, approval and permits and labor \& storage for all types of activities. Jupri et. al. [7] work, schedule of Dasu HPP was prepared in Primavera (P6) and then transferred to Pert-Master software and further analysis were made including simulations of schedule, cost and risks of projects as presented in next sections of the paper.

\subsection{Adopted Methodology}

The research methodology involved the questionnaire survey for identification of potential risks with their probabilities and impact. Data was collected from most relevant stakeholders and professionals working in HPP.

Pert-Master software has been used as primary tool for simulation and modeling of project schedule and cost. Pert-Master software has certain distinct advantages over other relevant software such as Microsoft Project or Primavera (P6). Only Pert-Master software is able to simulate schedule by using and interlinking risks with various project activities and thus give most probable duration of project, most probable cost of the project, critical risks sensitive to duration, critical risk sensitive to cost and statistically analyzed critical tasks/activities, which need due consideration for successful completion of project as Pert-Master often interprets the Primavera P3 data better than Primavera P6 [9].

After feeding all data in the software, Monte Carlo simulation was run at 1,000 iterations to generate most probable duration of project, most probable cost of the project, critical risks sensitive to duration, critical risk sensitive to cost and statistically analyzed critical tasks/ activities, which need due consideration for successful completion of project. Simulated schedule and budget was compared with planned one to find possible deviations, which may be eliminated by using mitigation measures proposed in the last section of the paper. Certain limitations were considered while modeling the schedule of Dasu HPP.

- Cost was taken as single resource, other subsets were not considered such as machinery, manpower etc.

- The main focus was the duration of implementation of the project.

- Weather modeling was not considered during simulation. Weather can be a significant factor in a project schedule, very often there is good data for estimating weather conditions, but it is difficult to understand the effect it can have on a very long schedule of around 3 years and more.

- Joint venture risks, communication risks, risks of variation in expertise, level of understanding were not included in the study.

Methodology was divided into four distinct parts as detailed below:

\subsubsection{Risk Identification}

All potential risks of project need to be carefully identified and assessed. Triangulation (three pronged) approach was used for identification of risks of Dasu HPP. On first step, risk identification was carried out through document reviewed. The referred documents included pre-feasibility studies, feasibility studies, basic 
design report, detailed design reports, reports on construction planning and methodology. Documents were also review from previous similar projects executed by WAPDA to identify the risks associated with such projects. On the Second step, interviews were conducted from experienced engineers and professionals working on Dasu HPP in different departments/divisions of WAPDA, Consultants, Contractors, JV Partners and Public. After thorough deliberations document reviews and interviews, total 130 risks were finally identified for Dasu HPP correlating step one and two, with the following breakup as shown in Table 2.

\subsubsection{Probability of Occurrence and Impact of Risks}

There are various hypotheses available in literature for estimating probabilities and impact of various risks. Some methods are statistical while others are mathematical. Some empirical (expert judgment) methods are also available among those some methods are conservative while other are optimistic and giving lower values of probabilities and impacts of various kinds of risks [1-3].

PMI (Project Management Institute), USA has given a standard for calculating Possibility of Occurrence and Impact Factor of risk given as can been seen from Table 3 .
There is a lot of subjectivity in PMI approach of calculating Possibility of Occurrence and Impact factor of each risk as mentioned in Table 2. It is very difficult to categorize the probability of occurrence in percentage terms and therefore researcher find difficulty in judging the risk and marking them as Very High Chances (90\%) to High Chances (75\%) and so on. Therefore, for this purpose, a mechanism has been developed in consultation with all process owners and stakeholders for selecting probability of each risk. Tables 3-5 give opportunity to the risk professional to select a frequency with a base frequency of $50 \%$. Neutral position of a risk, according to this mechanism will be $50 \%$ frequency. If there is a positive possibility of occurrence of risks, frequency higher than $50 \%$ will be selected. More the chances of occurrence, higher will be the frequency or vice versa. Similarly, the mechanism developed by the author, gives a risk professional the opportunity to assign separately the impact of risk in terms of time, cost or quality. Sometimes, it happens in an HPP, where cost is not too much implicit, it reduces the impact factor negatively downwards, however, it other indirect impact on time or quality is significant, which isignored if we use the PMI approach. To avoid the subjectivity of PMI approach to identify, analyze and quantify risks, a quantitative approach has been used and mentioned in Table 4 and will be used for selecting an impact factor to a risk in a three dimensional context of time, cost and quality to have three risk numbers separately [4].

TABLE 2. CLASSIFICATION OF RISKS

\begin{tabular}{|c|c|c|}
\hline No. & Major Area & Number of Risks \\
\hline 1. & Construction Risks & 15 \\
\hline 2. & Contractual Risks & 11 \\
\hline 3. & Engineering Risks & 6 \\
\hline 4. & HSE \& Security Risks & 10 \\
\hline 5. & Natural, Climatic \& Environmental Risks & 9 \\
\hline 6. & Procurement Risks & 7 \\
\hline 7. & Miscellaneous Risks & 130 \\
\hline
\end{tabular}

Mehran University Research Journal of Engineering \& Technology, Volume 38, No. 3, July, 2019 [p-ISSN: 0254-7821, e-ISSN: 2413-7219] 
Monte Carlo Simulation and Modeling of Schedule, Cost and Risks of Dasu Hydropower Project

TABLE 3. PROJECT MANAGEMENT INSTITUTE(PMI) PROBABILITY AND RISK IMPACT FACTOR [10]

\begin{tabular}{|c|c|c|c|}
\hline Possibility of Occurrence & $\begin{array}{c}\text { Probability } \\
(\%)\end{array}$ & Type and Level of Risk Impact & Impact Factor (I) \\
\hline Very High Chances & 90 & When maximum impact on scope, time and cost & 0.9 \\
\hline High Chances & 75 & $\begin{array}{c}\text { High impact on scope, medium impact on time and } \\
\text { lesser impact on cost }\end{array}$ & 0.6 \\
\hline Greater Chances & 60 & \multirow{2}{*}{$\begin{array}{l}\text { High impact on time, medium impact on scope, and } \\
\text { lesser impact on cost }\end{array}$} & \multirow{2}{*}{0.3} \\
\hline Possible & 45 & & \\
\hline Likely & 30 & \multirow{2}{*}{$\begin{array}{l}\text { When high impact on the cost of the project } \\
\text {, medium impact on time and lesser impact on scope }\end{array}$} & \multirow{2}{*}{0.1} \\
\hline Un-Likely & 15 & & \\
\hline
\end{tabular}

TABLE 4. CHANCES OF RISK OCCURRENCE AND ITS FREQUENCY FOR DASU HPP

\begin{tabular}{|c|c|c|}
\hline No. & Chances of Occurrence & Frequency (\%) \\
\hline 1 & Ultra high chances of occurrence & $>90$ \\
\hline 2 & Extremely High chances of risk occurrence & $>80$ \\
\hline 3 & Very high chances of risk occurrence & $>70$ \\
\hline 4 & High chances of occurrence & $=50$ \\
\hline 5 & Medium chance 50 - 50 (May or may not occur) & $>40$ \\
\hline 6 & Low chances of occurrence & $>30$ \\
\hline 7 & Very Low chances of occurrence & $>20$ \\
\hline 8 & Extremely Low chances of occurrence & $<20$ \\
\hline 9 & Ultra Low chances of occurrence & \\
\hline
\end{tabular}

TABLE 5. TYPE AND LEVEL OF RISK IMPACT \& IMPACT FACTOR

\begin{tabular}{|c|c|c|}
\hline No. & Chances of Occurrence & Frequency $(\%)$ \\
\hline \multicolumn{3}{|c|}{ Scope (Maximum Impact and Major Areas are Affected) } \\
\hline 1. & Very High Impact on Cost (>7\% cost increase) & \multirow{3}{*}{0.9} \\
\hline 2. & Very High Impact on Time (>7\% time increase) & \\
\hline 3. & Very High impact on Quality (unaccepted to the Client) & \\
\hline \multicolumn{3}{|c|}{ Scope (Normal Impact and Some Areas are Affected) } \\
\hline 1. & High Impact on Cost (4-7\% cost increase) & \multirow{3}{*}{0.6} \\
\hline 2. & High impact on Time (4-7\% time increase) & \\
\hline 3. & High impact on Quality (accepted to the Client by with major changes) & \\
\hline \multicolumn{3}{|c|}{ Scope (Minimum Impact) } \\
\hline 1. & Medium impact on Cost (2-4\% cost increase) & \multirow{3}{*}{0.3} \\
\hline 2. & Medium impact on Time (2-4\% time increase) & \\
\hline 3. & Medium impact on Quality (accepted to the Client by with minimum changes) & \\
\hline \multicolumn{3}{|c|}{ Scope (Insignificant Impact) } \\
\hline 1. & Low and Very Low impact on Cost $(<2 \%$ cost increase $)$ & \multirow{3}{*}{0.1} \\
\hline 2. & Low and Very Low impact on Time $(<2 \%$ time increase $)$ & \\
\hline 3. & Low and Very Low impact on Quality (insignificant) & \\
\hline
\end{tabular}

Mehran University Research Journal of Engineering \& Technology, Volume 38, No. 3, July, 2019 [p-ISSN: 0254-7821, e-ISSN: 2413-7219] 


\subsubsection{Data Collection}

Data was collected on designed questionnaire from 220 professionals associated to hydro power projects in various capacities working with national and international consultant organizations, contractors and client departments such as WAPDA, Planning Commission, P\&D Department, etc. Professionals were targeted for giving response on the questionnaire that hold design, contract administration, procurement, execution, environment, geology, health \& safety and infrastructures of HPP. The questionnaire was responded by 156 professionals. Every participant of the survey was to provide the frequency and impact of each risk. Knowing the fact that the impact of a risk can be upon any of variables like time, cost and quality, hence, in the questionnaire the respondents were asked to give their inputs for afore mentioned possibilities of occurrence and impact factor for each identified risk.

\subsubsection{Simulation and Modeling}

The schedule for Dasu, HPP was prepared in Primavera P6 software and then imported to Pert-Master software. All 130 identified risks were uploaded on the software and assigned to their relevant activities of the schedule to prepare the Risk-Based (simulated) Schedule and to find modeled cost of project. The basic aim of simulation was to find the deviation of Schedule and Budget from originally planned project. Moreover, it was intended to find the critical risks associated to the project. Probabilities of occurrence and impact of risks worked out with the help of experts as mentioned in section 2.2.2 and 2.2.3 were placed in software on the respective schedule of Dasu HPP. Quick Risks command was used for modeling of duration of the Project into three stages such as minimum duration, most likely and maximum duration, these all duration are based on the $\%$ remaining duration entered for the planning of the activities. Templated Quick Risk menu was used for adding uncertainty to the durations in terms of distribution shape and value such as low, medium and high, in order to overwrite the existing duration estimates.
Considering, possible risks and subsequent variation in time and cost of project, Monte Carlo simulation was run at 1,000 iterations. Simulation analyzed multiple scenarios of a model by repeatedly sampling values from the probability distributions for the uncertain variables and using those values given in Pert-Master software includes Simulated Schedule and Cost, Distribution Graphs, Tornado Graphs, Scatter Plot, Probabilistic Cash Flow and Criticality Index Report.

Triangular distribution was used in this research work for simulation purposes. The other Distribution Type like Uniform, Beta Pert and Enhanced do not match with the real situations at construction site.

Simulation worked out most probable duration of project, most probable cost of the project, critical risks sensitive to duration, critical risk sensitive to cost and criticality index of activities.

\section{RESULTS AND DISCUSSION}

\subsection{Results from Software}

After entering the software desired data regarding the activities and the risks, Monte Carlo Simulation was run on the schedule and simulated schedule of project was obtained which was further used to compare the different scenarios of project in terms of cost, delays and completion of the project. The main results are as follows:

\subsection{Simulated Schedule (Duration) of Dasu HPP}

Two scenarios were considered in Monet Carlo simulation schedule of Dasu HPP i.e. simulation with risk and simulation without risk. However, variation in activity duration vis-à-vis optimistic duration, pessimistic duration and most likely duration was in given in both scenarios. Simulation uses 80:100:120 distributions of optimistic, most likely and pessimistic duration of various project activities. The initial planned duration of project is 2556 days, which was worked out by conventional method of planning and estimation. Planned finished date 
is $29^{\text {th }}$ September, 2021. Against these deterministic values of duration and finish date of project, the simulated (most probable) duration and finish date for the Dasu HPP comes out to be 3113 days and $9^{\text {th }}$ March, 2023 respectively considering no risks in simulation.

Considering probable risks of project mapped with the various activities of schedule, simulated duration and finish date comes out to be 3760 days and $15^{\text {th }}$ January, 2025 respectively.

Some mitigation measures were applied to the risk to treat some risk, which were treatable. In this case, finish date and duration are $11^{\text {th }}$ June, 2024 and 3642 days respectively after applying control and mitigation measures for identified risks in post-mitigation scenario.

The most probable variations between the originally planned schedule and simulated schedule comes out to be is 648 days i.e. project is subjected to delays of 648 days if no risk mitigation is considered. However, after plausible mitigation of the identified risks i.e. in postmitigated scenario, project is expected to delay by 430 days subject to provision of funds as per plans as shown in Fig. 1(a-b).

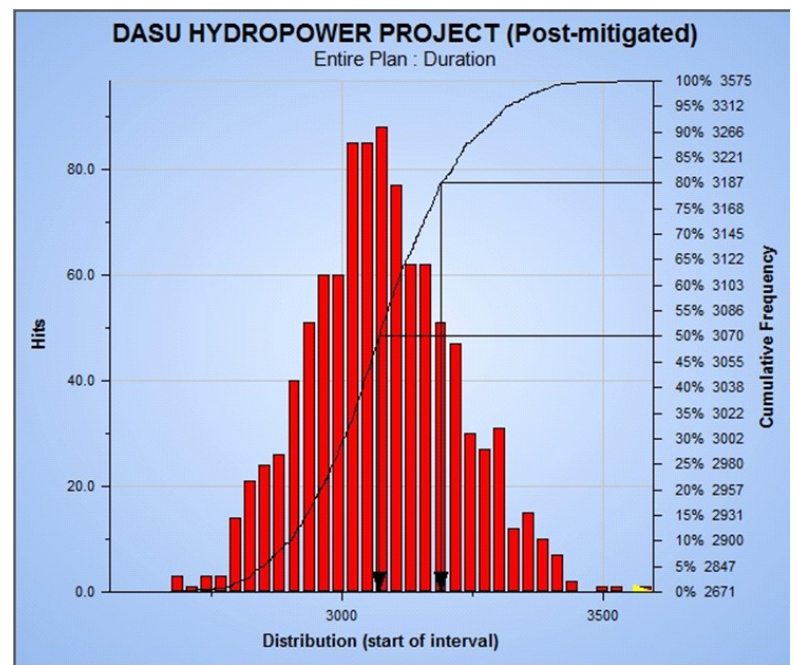

FIG. 1(a). POST MITIGATED SIMULATED ENTIRE PLAN DURATION OF DASU HPP
The Duration Sensitivity of a task is a measure of the correlation between its duration and the duration (or dates) of the project (or a key task or summary). PertMaster analysis calculated top ten duration sensitive activities with respect to chances to overall delay of Dasu HPP are mentioned in Fig. 2.

\subsection{Simulated Cost and Cost Sensitive Activities}

The planned deterministic cost of project is PKR 406,128 Million. Post mitigate cost of Dasu HPP is PKR 848,360 Million, taking $80 \%$ as the most probable values $\mathrm{P} 80$ for entire plan, simulated cost of Dasu HPP with risks for post-mitigated cost is PKR 1,214,860 Million with applying control measures for proposed risks as shown in Fig. 3.

The variations between the entire plan and pre-mitigated is PKR 1,188,569 Million, the entire plan and postmitigated is PKR 801,922 Million, and finally between premitigated and post-mitigated is PKR 386,647 Million respectively.

The cost sensitivity of a task is a measure of the correlation between its cost and the cost of the project (or a key task or summary). Analysis obtained with the

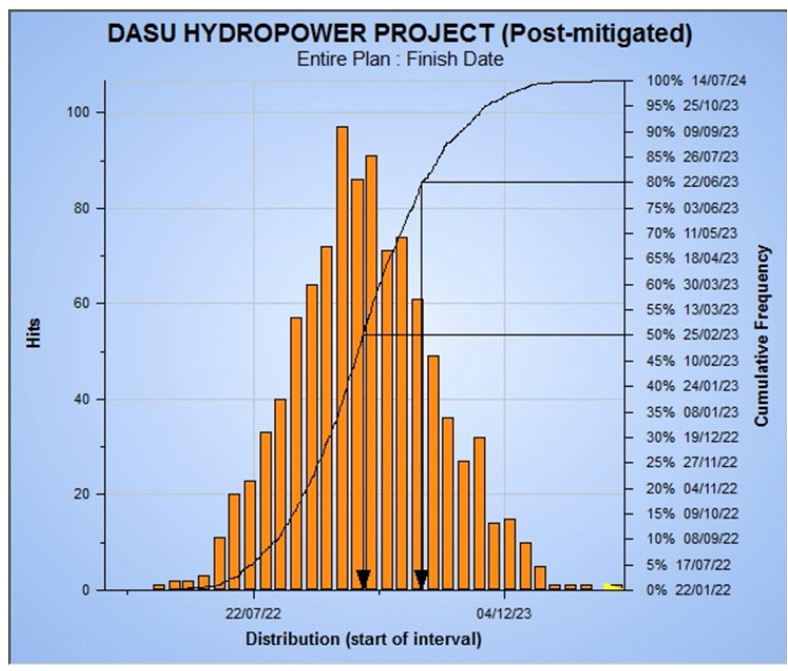

FIG. 1(b). POST MITIGATED SIMULATED FINISH DATE OF $D A S U H P P$

Mehran University Research Journal of Engineering \& Technology, Volume 38, No. 3, July, 2019 [p-ISSN: 0254-7821, e-ISSN: 2413-7219] 
help of Pert-Master simulation highlighted cost sensitive activities of Dsu HPP, which have more chances to increase the overall project cost of Dasu HPP. Top ten activities with respect to chances to increase overall cost of Dasu HPP are mentioned in Fig. 4.

\subsection{Top Ten Critical Risks Evaluated by the Pert-Master Software Impacting Schedule and Cost of Dasu HPP}

Simulation worked out top ten critical risks influencing duration and cost of the project described in Table 6.

\subsection{Top Ten Critical Activities (Tasks) Evaluated by Pert-Master}

The CI (Criticality Index) is proportion of iteration out of total simulation cycles i.e. 1,000 in which it remained critical. CI is a statistical evaluation of critical activities, which is much more reliable as compare to Critical Path of project activities calculated by CPM (Critical Path Method) of project scheduling. After simulation, top ten activities vis-à-vis criticality index were analyzed by the software as mentioned Table 7.

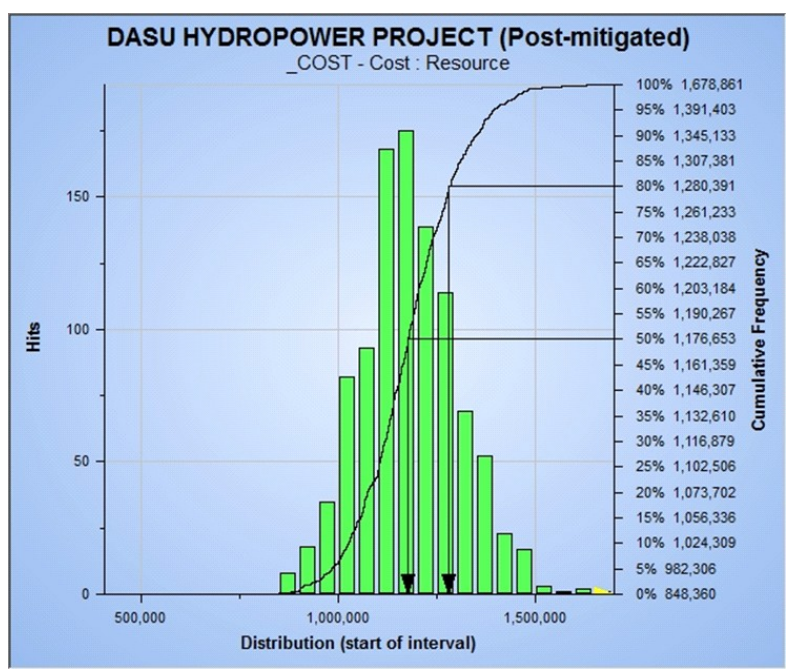

FIG. 3. COST DISTRIBUTION GRAPH OF DASU HPP

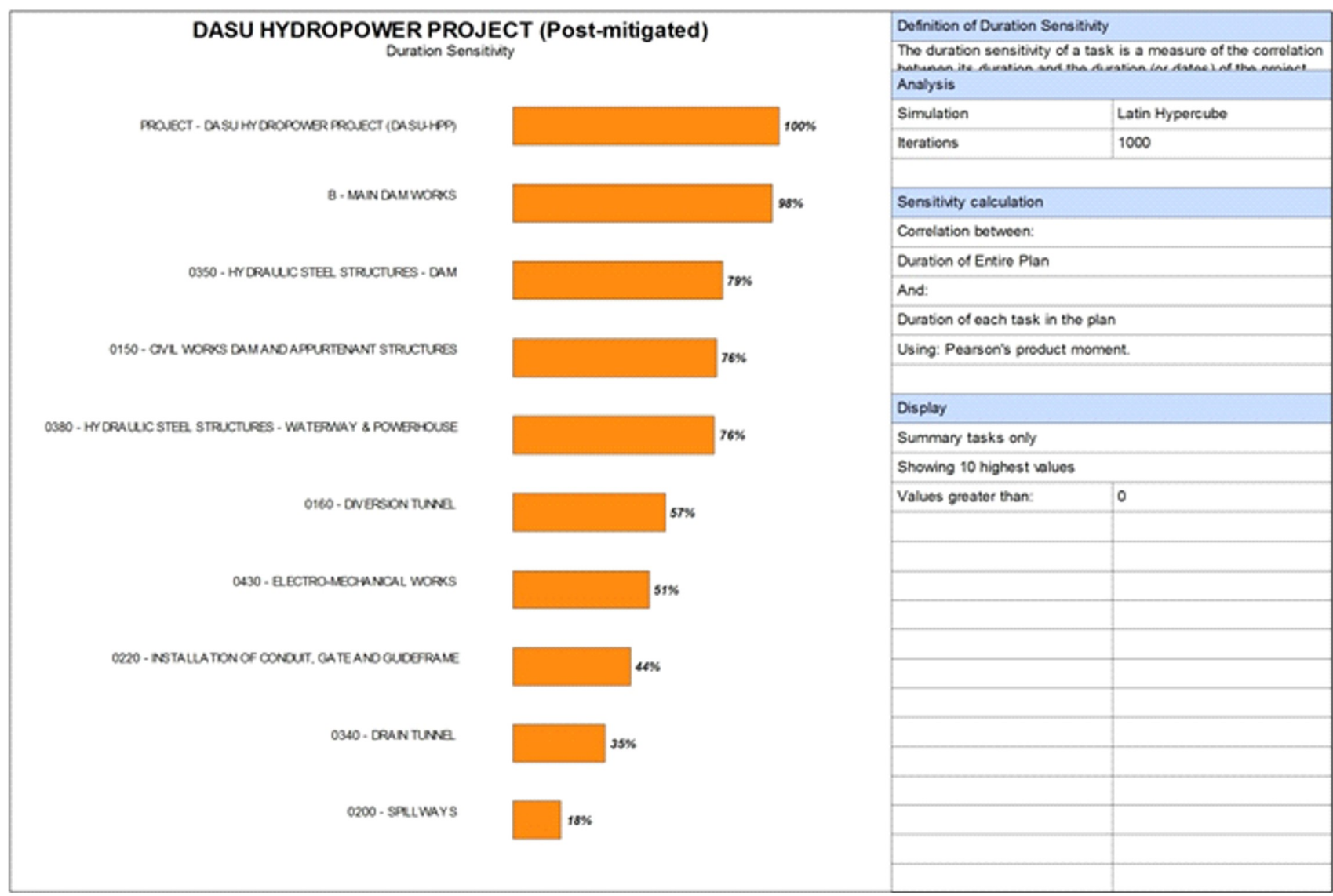

FIG. 2. TEN TOP ACTIVITIES HAVING HIGHEST DURATION SENSITIVITY ON OVERALL PROJECT DURATION 


\subsection{Risk Mitigation Measures}

After thorough literature review [1-3,5,9] and discussion with internal and external stakeholders including Client, Joint Venture Partners, Consultants, Contractors, Sub Contractors, Suppliers and other experts, strategies to mitigate the critical risks evaluated by Pert-Master software (Table 6) were devised along with the responsibility of concerned stakeholder. In that way a responsibility matrix was prepared for the critical risks of the project as shown in the Table 8 .

\section{CONCLUSION}

For this research, a methodology was designed and adopted for developing a risk based scheduling of Dasu
HPP. For risk based scheduling, risk identification, classification, analysis, and quantifications of risks were made. Monte Carlo simulation was run by using PertMaster software. Based on the software analysis, it is concluded that project is highly risky project. The initial planned duration of project is 2556 days, which was worked out by conventional method of planning and estimation. Planned finished date is $29^{\text {th }}$ September, 2021. Against these deterministic values of duration and finish date of project, the simulated (most probable) duration and finish date for the Dasu HPP comes out to be 3760 days and $15^{\text {th }}$ January, 2025 respectively. Mitigation measures were applied to the risk to treat some risks, which were treatable. In this case, finish date and duration

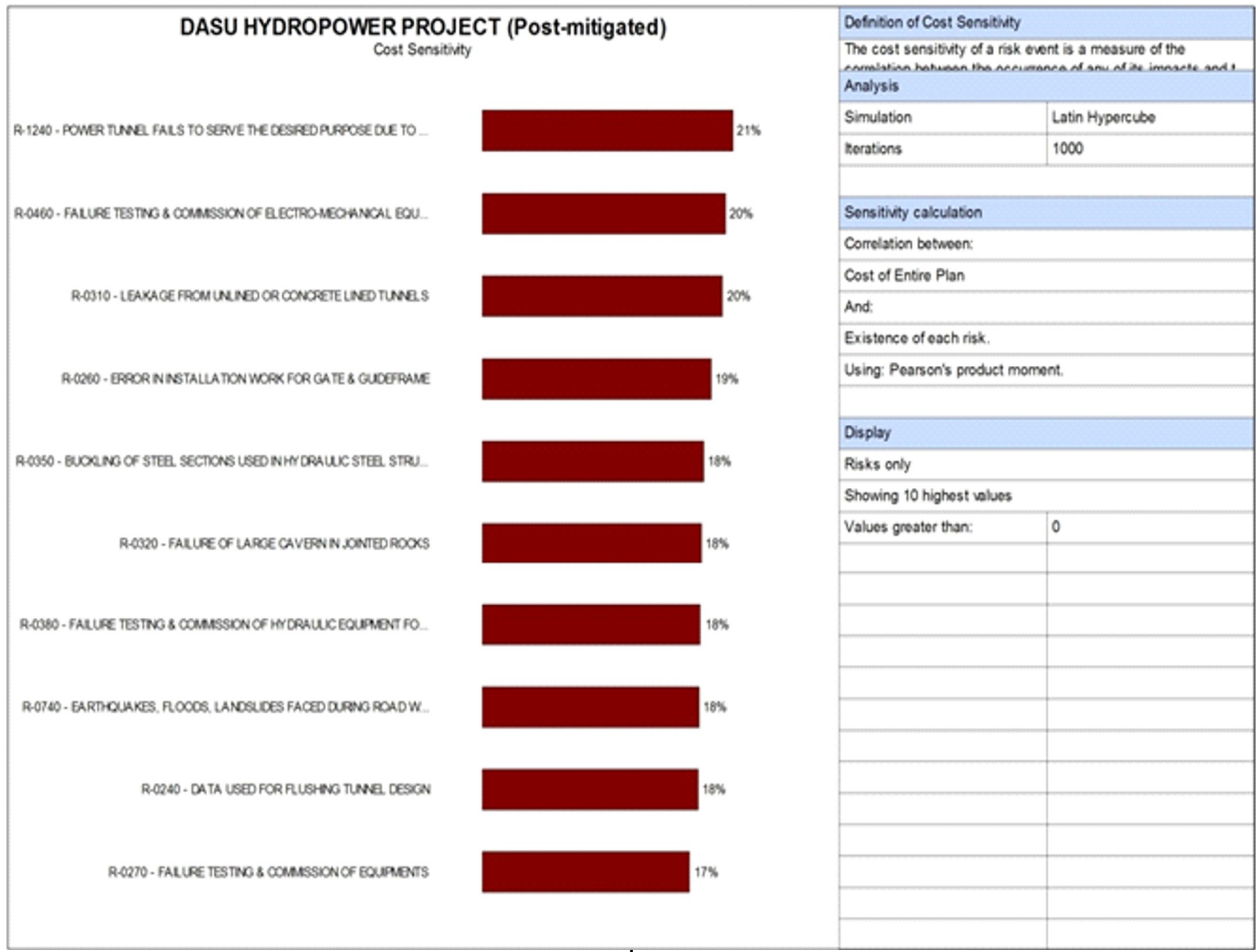

FIG. 4. TEN TOP ACTIVITIES HAVING HIGHEST COST SENSITIVITY ON OVERALL PROJECT COST

Mehran University Research Journal of Engineering \& Technology, Volume 38, No. 3, July, 2019 [p-ISSN: 0254-7821, e-ISSN: 2413-7219] 
of project comes out to be $11^{\text {th }}$ June, 2024 and 3642 days respectively after applying control and mitigation measures for identified risks in post-mitigation scenario at $\mathrm{P}-80$.

Project is prone to delayand if no substantial measure is taken project will be delayedupto 1204 days. If some mitigation measures are adopted to control the risks, completion of project will be delayed by around 648 days. However, if risks are properly mitigated, this delay may be reduced to maximum 430 days. Simulation tells us that there is wide possibility that project will be completed in almost triple the cost of its initial planned cost keeping in view the potential risks, existing project execution pace and deployment of resources. However, if the critical risks are mitigated, simulated cost will remain almost double of the

TABLE 6. TOP TEN CRITICAL RISKS IMPACTING DURATION AND COST OF DASU HPP

\begin{tabular}{|c|c|c|c|}
\hline Risk ID & 10 Critical Risks Impacting Duration & Risk ID & 10 Critical Risks Impacting Cost \\
\hline R-0460 & Litigation (dispute during testing \& commission) & R-1030 & Failure testing \& commission of transmission line equipment \\
\hline R-0140 & $\begin{array}{l}\text { Identification of design errors of diversion tunnels } \\
\text { during execution }\end{array}$ & R-1240 & $\begin{array}{l}\text { Redesign due change in alignment of power tunnel } \\
\text { due to geology (presence of soft rock) }\end{array}$ \\
\hline R-0260 & Delayed procurement of gates \& guide frames & R-0860 & Cracking of girder during handling \& placing \\
\hline R-0270 & Failure(rework) for testing \& commission of equipment & R-1110 & Damage of grid station equipment during handling \\
\hline R-1180 & Risk of possession at site & R-1250 & Over design of diversion tunnel due to error in hydrological data \\
\hline R-0230 & Unavailability of key resources for spillways & R-1070 & Chances of hard strata encountered during switchyard civil works \\
\hline $\mathrm{R}-1240$ & $\begin{array}{l}\text { Redesign due change in alignment of power tunnel due to geology } \\
\text { (presence of soft rock) }\end{array}$ & $\mathrm{R}-1230$ & $\begin{array}{l}\text { Quality issue regarding starter dam } \\
\text { (tension crack can appear) }\end{array}$ \\
\hline R-0720 & Compaction fails for sub-base $\&$ base (rework) & R-0990 & Variation in material specifications \\
\hline R-1060 & $\begin{array}{l}\text { Contractor's lack of managerial skills } \\
\text { (scope, time, quality, resources etc.) }\end{array}$ & R-1130 & $\begin{array}{c}\text { Change in contract price due to large variation } \\
\text { of scope of work }\end{array}$ \\
\hline R-1080 & Delayed arrival of panels (RP, CP etc.) for switchyard & R-0760 & Quality issue in drainage $\&$ erosion works \\
\hline
\end{tabular}

TABLE 7. TOP TEN CRITICAL RISKS

\begin{tabular}{|c|c|c|}
\hline No. & Task ID & Task Description \\
\hline 1. & 0030 & Land Development \\
\hline 2. & 0160 & Diversion Tunnel \\
\hline 3. & 0490 & Testing \& Commissioning of Electro-Mechanical Equipment \\
\hline 4. & 0370 & Commissioning Works of HSS for Dam \\
\hline 5. & 0420 & Commissioning Works of HSS for Water Ways \& Power House \\
\hline 6. & 0170 & Starter Dam U/S and D/S \\
\hline 7. & 0180 & Integrated Coffer Dam \\
\hline 8. & 0190 & Concrete for Dam \& Appurtenant Structures \\
\hline 9. & 0200 & Spill ways Works \\
\hline 10. & 0220 & Installation of Conduit, Gate \& Guide frames for Dam \& Appurtenant Structures \\
\hline
\end{tabular}

Mehran University Research Journal of Engineering \& Technology, Volume 38, No. 3, July, 2019 [p-ISSN: 0254-7821, e-ISSN: 2413-7219] 
initially planned cost. Based on the analysis, the project stakeholders of Dasu HPP should focus on time and cost sensitive activities, critical project risks as well as the critical activities to complete the project successfully.

TABLE 8. MITIGATION MEASURES OF CRITICAL RISK FOR DASU HPP VIS-A-VIS TIE AND COST

\begin{tabular}{|c|c|c|c|}
\hline Risk ID & Major Risk & Strategies to Mitigate Risks & Responsibility \\
\hline R-0460 & $\begin{array}{l}\text { Litigation (Dispute During } \\
\text { Testing \& Commission) }\end{array}$ & $\begin{array}{l}\text { Read the E\&M details in-concern with the civil drawings. } \\
\text { Do the installation of E\&M specialized parts as per operational manual }\end{array}$ & $\begin{array}{c}\text { Contractor } \\
\text { Construction Manager }\end{array}$ \\
\hline R-0140 & $\begin{array}{l}\text { Identification of Design Errors of } \\
\text { Diversion Tunnels } \\
\text { During Execution }\end{array}$ & $\begin{array}{c}\text { Check \& analyze the design data before the start of execution of diversion tunnel. } \\
\text { Prefer the software interpretations in order to avoid error }\end{array}$ & $\begin{array}{l}\text { Consultant } \\
\text { Project Manager } \\
\text { (Design) }\end{array}$ \\
\hline $\mathrm{R}-0260$ & $\begin{array}{l}\text { Delayed Procurement of } \\
\text { Gates \& Guide frames }\end{array}$ & $\begin{array}{l}\text { Quickly place order as the concreting works finish } \\
\text { Follow up the procurement order no weekly }\end{array}$ & $\begin{array}{l}\text { Contractor } \\
\text { Project Manager }\end{array}$ \\
\hline $\mathrm{R}-0270$ & $\begin{array}{c}\text { Failure(Rework) For } \\
\text { Testing \& Commission of Equipment }\end{array}$ & $\begin{array}{l}\text { Follow up the verification of the connection details } \\
\text { Do the testing of equipment as per standard }\end{array}$ & $\begin{array}{l}\text { Contractor } \\
\text { Construction Manager }\end{array}$ \\
\hline R-1180 & Risk of Possession At Site & $\begin{array}{l}\text { Land acquisition process should be started parallel with the detailed drawings. } \\
\text { Do the stakeholder consultation with locals and communities before the award of } \\
\text { contracts. }\end{array}$ & Government/Client \\
\hline $\mathrm{R}-0230$ & $\begin{array}{l}\text { Unavailability of Key } \\
\text { Resources for Spillways }\end{array}$ & $\begin{array}{c}\text { Confirm all the concerned resources such as material, manpower \& machineries } \\
\text { before the start of spillways }\end{array}$ & $\begin{array}{c}\text { Contractor } \\
\text { Project Manager }\end{array}$ \\
\hline $\mathrm{R}-1240$ & $\begin{array}{l}\text { Redesign Due Change In Alignment } \\
\text { Of Power Tunnel Due To Geology } \\
\text { (Presence Of Soft Rock) }\end{array}$ & $\begin{array}{l}\text { Improve the data assessment for design of power tunnels } \\
\text { Do the geological survey and editing of rocks carefully with new modern } \\
\text { instruments. } \\
\text { Use 3-d modeling of tunnels before its drilling in rocks }\end{array}$ & $\begin{array}{l}\text { Contractor } \\
\text { Construction Manager }\end{array}$ \\
\hline R-0720 & $\begin{array}{c}\text { Compaction Fails For Sub-Base \& } \\
\text { Base (Rework) }\end{array}$ & $\begin{array}{c}\text { Improve compaction method. } \\
\text { Verify number of passes of roller } \\
\text { Use materials containing negligible impurities }\end{array}$ & $\begin{array}{c}\text { Contractor } \\
\text { Construction Manager }\end{array}$ \\
\hline $\mathrm{R}-1060$ & $\begin{array}{l}\text { Contractor's Lack of Managerial } \\
\text { Skills (Scope, Time, Quality, } \\
\text { Resources Etc.) }\end{array}$ & $\begin{array}{l}\text { Select Project Manager having similar experience } \\
\text { Do prequalification of contractor technical ability } \\
\text { Do prequalification of contractor financial ability }\end{array}$ & $\begin{array}{l}\text { Contractor } \\
\text { Owner }\end{array}$ \\
\hline R-1080 & $\begin{array}{l}\text { Delayed Arrival of Panels (RP,CP } \\
\text { etc.) for Switchyard }\end{array}$ & $\begin{array}{l}\text { Quickly place order as the civil works for panels completed } \\
\text { Follow up the procurement order no weekly }\end{array}$ & $\begin{array}{l}\text { Contractor } \\
\text { Project Manager }\end{array}$ \\
\hline $\mathrm{R}-1030$ & $\begin{array}{l}\text { Failure Testing \& Commission of } \\
\text { Transmission Line Equipment }\end{array}$ & $\begin{array}{l}\text { Do inspection of the connection details } \\
\text { Do the testing of equipment as per standard manual }\end{array}$ & $\begin{array}{l}\text { Contractor } \\
\text { Construction Manager }\end{array}$ \\
\hline $\mathrm{R}-0860$ & $\begin{array}{c}\text { Cracking Of Girder During Handling } \\
\text { \& Placing }\end{array}$ & $\begin{array}{l}\text { Do loading \& unloading of girders carefully by mechanical means } \\
\text { Do not lift the girders which are curing process }\end{array}$ & $\begin{array}{l}\text { Contractor } \\
\text { Construction Manager }\end{array}$ \\
\hline $\mathrm{R}-1110$ & $\begin{array}{c}\text { Damage of Grid Station Equipment } \\
\text { During Handling }\end{array}$ & $\begin{array}{l}\text { Do loading \& unloading of gird station equipment carefully by mechanical means } \\
\text { Use manufacturer / vendor / supplier team for handling \& installation works }\end{array}$ & $\begin{array}{l}\text { Contractor } \\
\text { Construction Manager }\end{array}$ \\
\hline $\mathrm{R}-1250$ & $\begin{array}{l}\text { Over Design of Diversion Tunnel } \\
\text { Due to Error In Hydrological Data }\end{array}$ & $\begin{array}{l}\text { Verify the Hydrological data before the start of works for diversion tunnels } \\
\text { Enhance the software for the design of tunnels PHASE-2 }\end{array}$ & $\begin{array}{l}\text { Consultant } \\
\text { Project Manager } \\
\text { (Design) }\end{array}$ \\
\hline $\mathrm{R}-1070$ & $\begin{array}{c}\text { Chances of Hard Strata } \\
\text { Encountered During Switchyard } \\
\text { Civil Works }\end{array}$ & $\begin{array}{l}\text { Use mechanical tools \& equipment for the hard rocks } \\
\text { Use of explosive can also be encouraged whenever required }\end{array}$ & $\begin{array}{l}\text { Consultant } \\
\text { Project Manager } \\
\text { (Design) }\end{array}$ \\
\hline $\mathrm{R}-1230$ & $\begin{array}{l}\text { Quality Issue Regarding Starter Dam } \\
\text { (Tension Crack Can Appear in } \\
\text { Concrete) }\end{array}$ & $\begin{array}{l}\text { Use vibrating instruments for the better compaction of concrete } \\
\text { use approved curing chemical \& construction chemical during batching of concrete } \\
\text { ingredients }\end{array}$ & $\begin{array}{c}\text { Contractor } \\
\text { Construction Manager }\end{array}$ \\
\hline R-0990 & Variation In Material Specifications & $\begin{array}{l}\text { Do focus on the available materials in market } \\
\text { Avoid much changes in the design \& scope of work }\end{array}$ & $\begin{array}{c}\text { Contractor } \\
\text { Project Manager }\end{array}$ \\
\hline R-1130 & $\begin{array}{l}\text { Change In Contract Price Due to } \\
\text { Large Variation of Scope of Work }\end{array}$ & $\begin{array}{c}\text { Define the scope of work properly } \\
\text { Do the proper survey work to avoid change in the scope of work } \\
\text { Do the good co-ordination between the stakeholders }\end{array}$ & $\begin{array}{l}\text { Contractor } \\
\text { Project Manager }\end{array}$ \\
\hline $\mathrm{R}-0760$ & $\begin{array}{c}\text { Quality Issue In Drainage \& Erosion } \\
\text { Works }\end{array}$ & $\begin{array}{l}\text { Improve the quality of concrete by improving compaction tools } \\
\text { Use the approved waterproof material }\end{array}$ & $\begin{array}{l}\text { Contractor } \\
\text { Construction Manager }\end{array}$ \\
\hline
\end{tabular}

Mehran University Research Journal of Engineering \& Technology, Volume 38, No. 3, July, 2019 [p-ISSN: 0254-7821, e-ISSN: 2413-7219] 


\section{ACKNOWLEDGEMENT}

Research was conducted as requirement for the award of MS Degree under Superior University. Support and cooperation of Superior University is acknowledged in this regard. Further, input of officials from Planning Division, Joint Venture Partners, Consultants and Contractor and Sub Contractors is highly appreciated. Efforts and inputs from high caliber professionals and engineers of Engineering Department, Procurement Department, Contact Department, and Environment Department of WAPDA are highly appreciated and acknowledged, without which this research couldn't be concluded successfully.

\section{REFERENCES}

[1] http://www.wapda.gov.pk/phocadownload/ DASU_Envroin/ESA-Main_Report_Dasu\%20HPP.pdf (Accessed on: 26.02.2018)

[2] https://www.pmi.org/learning/library/earned-valuemanagement-cost-index-6427 (Accessed on: 27.08.2018).

Mubin, S., Ahmed, M., and Sial, J., "Terminal Evaluation of Public Sector Development Projects: An Analysis of 85 Evaluated Development Projects of Punjab Province", Pakistan Journal of Engineering \& Applied Sciences, Volume 9, pp. 58-76, 2011.
Mubin, S., and Mubin, G., "Risk Analysis for Construction and Operation of Gas Pipeline Projects in Pakistan", Pakistan Journal of Engineering \& Applied Sciences, Volume 2, pp. 26-37, 2008.

[5] Mubin, S., and Mannan, A., "Innovative Approach to Risk Analysis and Management of Oil and Gas Sector EPC Contracts in Contractor's Perspective", Journal of Business \& Economics, Volume 5, No. 2, pp. 149-170, 2013.

[6] Bowles, D.S., "From Portfolio Risk Assessment to Portfolio Risk Management”, ANCOLD Bulletin, Volume 137, pp. 13-32, 2007.

[7] Jiang, H., Peng, L., Qixiang, F., and Maoshan Q., "RealTime Safety Risk Assessment Based on a Real-Time Location System for Hydropower Construction Sites", The Scientific World Journal, Volume 2014, pp. 14-20, 2014.

[8] Jupri, N., and Malim, R.M., "Risk Analysis of Construction Project Scheduling Using Pert and Monte Carlo Simulation", International Journal of Accounting and business Management, Volume 1, No. 1, pp. 83-91, 2013.

[9] http://www.prcsoftware.com/oracle-primavera-riskpertmaster-import-check-tab (Accessed on: 26.05.2018)

[10] A Guide to Project Management Body of Knowledge (PM Book Guide) 6th Edition, Project Management Institute, pp. 141-142, 2000. 